\title{
Bacterial artificial chromosomes improve recombinant protein production in mammalian cells Leander Blaas $^{\dagger 1}$, Monica Musteanu ${ }^{\dagger 1}$, Robert Eferl ${ }^{1}$, Anton Bauer ${ }^{2}$ and Emilio Casanova*1
}

Address: ${ }^{1}$ Ludwig Boltzmann Institute for Cancer Research (LBI-CR), Währinger Str. 13a, A-1090 Vienna, Austria and 2f-star, Gastgebgasse 5-13, A-1230 Vienna, Austria

Email: Leander Blaas - Leander.Blaas@lbicr.lbg.ac.at; Monica Musteanu - monica.musteanu@lbicr.lbg.ac.at;

Robert Eferl - Robert.Eferl@lbicr.lbg.ac.at; Anton Bauer - anton.bauer@f-star.com; Emilio Casanova* - emilio.casanova@lbicr.lbg.ac.at

* Corresponding author †Equal contributors

Published: 14 January 2009

BMC Biotechnology 2009, 9:3 doi:10.1 I86/1472-6750-9-3
Received: 3 September 2008

Accepted: 14 January 2009

This article is available from: http://www.biomedcentral.com/1472-6750/9/3

(c) 2009 Blaas et al; licensee BioMed Central Ltd.

This is an Open Access article distributed under the terms of the Creative Commons Attribution License (http://creativecommons.org/licenses/by/2.0), which permits unrestricted use, distribution, and reproduction in any medium, provided the original work is properly cited.

\begin{abstract}
Background: The development of appropriate expression vectors for large scale protein production constitutes a critical step in recombinant protein production. The use of conventional expression vectors to obtain cell lines is a cumbersome procedure. Often, stable cell lines produce low protein yields and production is not stable over the time. These problems are due to silencing of randomly integrated expression vectors by the surrounding chromatin. To overcome these chromatin effects, we have employed a Bacterial Artificial Chromosome (BAC) as expression vector to obtain stable cell lines suitable for protein production.
\end{abstract}

Results: In this work, we explore the efficacy of a Bacterial Artificial Chromosome based vector applied to production of the constant region of the human IgGI. Direct comparison of bulk HEK 293 cell cultures generated with a "conventional" vector or with a BAC-based vector showed that the BAC-based vector improved the protein yield by a factor of I0. Further analysis of stable cell clones harboring the BAC-based vector showed that the protein production was directly proportional to the number of integrated BAC copies and that the protein production was stable for at least 30 passages.

Conclusion: Generation of stable cell clones for protein production using Bacterial Artificial Chromosomes offers a clear advantage over the use of conventional vectors. First, protein production is increased by a factor of 10 ; second, protein production is stable overtime and third, generation of BAC-based expression vectors does not imply a significant amount of work compare to a conventional vector. Therefore, BAC-based vectors may become an attractive tool for protein production.

\section{Background}

Recombinant protein production in mammalian cells is an important topic in biotechnology [1]. One of the critical steps in the production of recombinant proteins is the isolation of stable single cell clones expressing high levels of the protein of interest. Commonly, this is achieved by random genomic integration of a vector containing a promoter, a gene of interest and a selectable marker. 
Although this method is simple and straight forward, it lacks of reproducibility. Expression from such vectors is substantially influenced by the surrounding chromatin to the integration site and tends to be silenced over time. This makes the selection of suitable clones a tedious and time consuming procedure [1]. Several strategies have been developed to overcome the positional effects of the adjacent chromatin. For example, "anti-repressor" elements flanking the vectors [2] have been used or vectors have been integrated specifically into chromosomal loci with open chromatin [3]. Ideally, a vector for recombinant protein production should display three features: 1) expression should be independent of the integration site in the genome, 2) expression should correlate with the number of integrated transgene copies and 3) expression should be maintained over time. Interestingly, large vectors that fulfill these criteria such as Bacterial Artificial Chromosomes (BACs) have been widely used for generation of transgenic mice [4] but not for production of recombinant proteins. BACs are vectors derived from the $F$ factor of E. coli that are maintained as low copy replicons. BACs offer a clear advantage compared to "classical expression vectors": Due to their large cloning capacity (up to $300 \mathrm{~Kb}$ ), BACs can accommodate most (if not all) of the elements that are responsible for the expression of a gene of interest. Thus, BACs can be considered as complete expression units. Consequently, expression from BACs based vector is less affected by the surrounding chromatin to their insertion site in a host genome. In this sense, BACs containing genes that are considered as open chromatin (highly transcribed), such as Rosa26, $\beta$-actin, Gapdh etc. are attractive tools in the field of eukaryotic recombinant protein production. On the other hand, due to their large size, BACs can not be manipulated using traditional cloning techniques. Modification of BACs is done via homologous recombination in E. coli (recombineering), however, there are several existing methods that allow to modify a BAC via homologous recombination in E. coli, thus making the use of BACs as expression vectors a relative simple task [5-7]. In this work, we explore the suitability of a BAC containing the Rosa2 6 locus as expression vector applied to the production of the Fc fragment of the constant region of human IgG1 in HEK 293 cells.

\section{Methods \\ Plasmids and cell culture}

The CAGGS Fc expression vector was assembled by conventional cloning methods and is flanked by two attB sites (C31 integrase recognition sites). The Rosa26 BAC CAGGS Fc $\mathrm{BAC}$ vector was generated as previously described [8]. Briefly, the CAGGS Fc vector was recombined into a BAC containing the Rosa26 locus using C31 mediated cassette exchange into the exon 2 of the Rosa26 antisense transcript.
To establish the bulk cultures, $24 \mu \mathrm{g}$ CAGGS Fc and

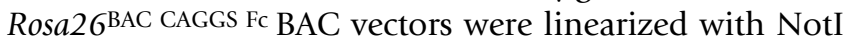
and transfected into HEK 293 cells using Lipofectamine 2000 (Invitrogen). Two days after transfection, G418 (800 $\mu \mathrm{g} / \mathrm{ml}$ ) was added to the media (DMEM high glucose, $10 \%$ FCS, supplemented with glutamine, pyruvate and non essential aminoacids). Selection was carried out over 14 days. Thereafter, all the cultures were grown in the absence of G418 and Fc protein production in the bulk cultures was measured 1 week later.

\section{Human IgGI-Fc protein determination}

$5 \times 10^{5}$ cells were seeded into each single well of a 6 well plate in $2 \mathrm{ml}$ of medium. 72 hours after seeding, the Fc protein concentration was measured in the supernatants using an ELISA assay. For the ELISA, goat anti-human-IgG (Fc specific) $\mathrm{F}\left(\mathrm{ab}^{\prime}\right) 2$ fragment (Sigma I-3391) was adsorbed at $1 \mu \mathrm{g} / \mathrm{ml}$ onto microwells of a Maxisorp plate over night at $4{ }^{\circ} \mathrm{C}$, followed by blocking with $5 \%$ BSA in PBS for $1 \mathrm{~h}$ at $25^{\circ} \mathrm{C}$. After washing, the samples and the standard, respectively, were added in dilution series to the blocked microwells and incubated for $1 \mathrm{~h}$ at $25^{\circ} \mathrm{C}$. The plate was washed and bound Fc was detected by Protein A - HRP (SIGMA P-8651) diluted 1:70000 in PBS/BSA followed by staining with TMB substrate solution (Sigma T0446). The ELISA was measured at $450 \mathrm{~nm}$ with the reference wavelength $630 \mathrm{~nm}$.

\section{Rosa26BAC CAGGS FC copy number analysis}

The Rosa26BAC CAGGS Fc culture was enriched twice using eYFP FACS sorting. Single clones were established using a dilution technique. Cells were seeded in 96 well plates at 0.5 cells per well. Clones were expanded progressively up to $10 \mathrm{~cm}$ dish, at this point (confluent $10 \mathrm{~cm}$ dish), cells were considered passage 1. During subcloning, expansion and subsequence analysis of the cultures no selective pressure was used. The number of transgene copies in the single cell clones (at passage 1) was quantified by real time PCR with genomic DNA as template. The Rosa26 BAC was amplified with oligos RosaF 5' TCTTGTCCTTTTACCTCCCTTGTA RosaR 5' GAACATATTCAAAACACCAGGATTT. These oligos recognize a sequence that is identical in the Rosa26 BAC (from murine origin) and in the endogenous Rosa26 locus (HEK cells, from human origin). The $\beta$-actin locus was amplified with oligos, actinF 5 ' TCATGTTTGAGACCTTCAACACC and actinR 5' GATCTTCATGAGGTAGTCAGTCAGGT as internal control to normalize the amount of genomic DNA used.

\section{Results}

In order to test the efficacy of BACs in the production of recombinant proteins, we have generated two expression vectors: The CAGGS Fc vector, which consists of a CAGGS promoter [9], the Fc fragment (i.e. hinge, $\mathrm{C}_{\mathrm{H}} 2$ and $\mathrm{C}_{\mathrm{H}} 3$ ) of human IgG1 as gene of interest $(\mathrm{Fc})$ containing a leader 
peptide for secretion [10], an IRES/eYFP reporter and a PGK-neomycin cassette. The second vector, Rosa26 $6^{\mathrm{BAC}}$ CAGGS Fc, consists of the CAGGS Fc vector that has been recombined into a BAC backbone containing the Rosa26 locus (Figure 1A). HEK 293 cells were transfected with the

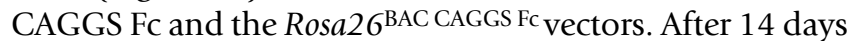
of G418 selection we obtained more than 2000 G418 resistant clones for the CAGGS Fc vector and 200-300

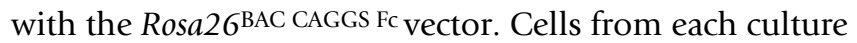
were pooled and two bulk cultures for the CAGGS FC and Rosa26BAC CAGGS Fc vectors respectively were established.
Analysis of the Fc protein production in the supernatants showed a yield of 0.5 and $5.7 \mathrm{pg} / \mathrm{cell} / \mathrm{day}$ in the CAGGS Fc and the Rosa26 $6^{\mathrm{BAC}}$ CAGGS Fc bulk cultures, respectively (Figure 1B), demonstrating that the use of a BAC-based vector improves the protein production substantially.

Next, we analyzed the correlation between the number of transgene copies and the Fc protein yield. 12 subclones

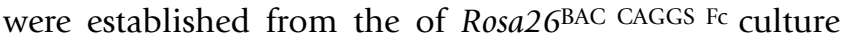
that harbored 1 to 55 copies of the transgene. Protein yield in the supernatants of these cultures correlated with

A
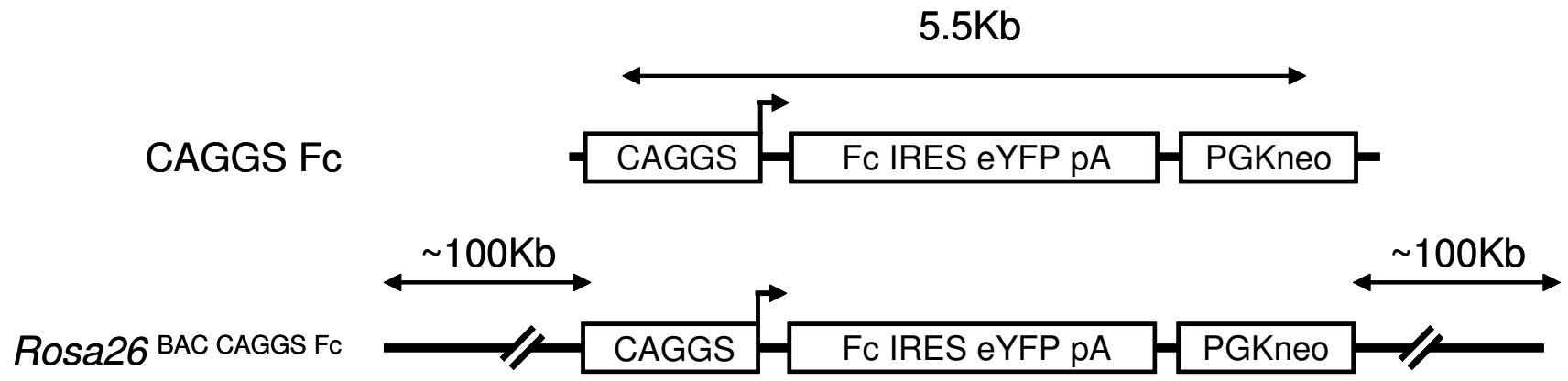

B

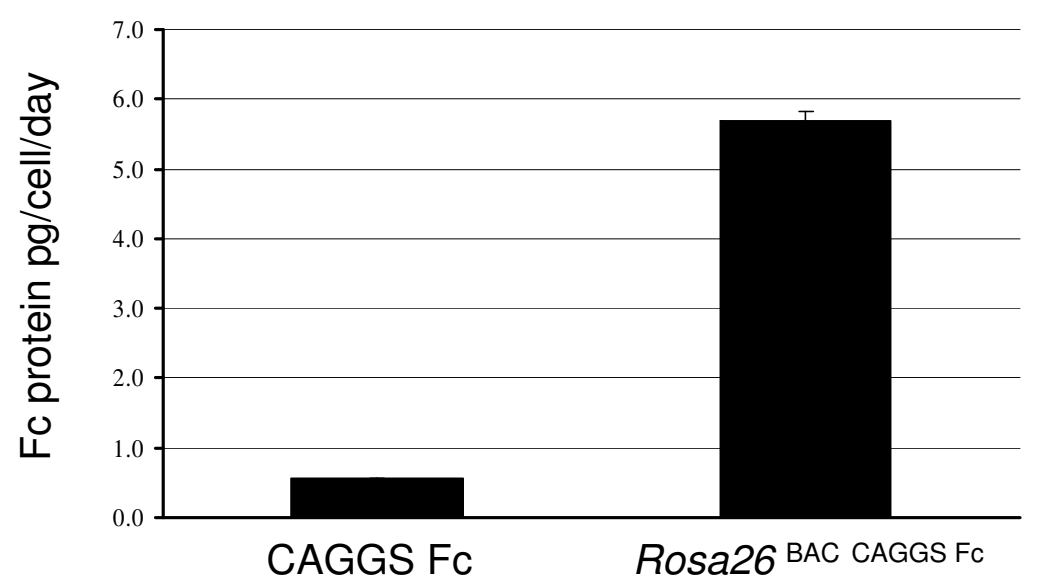

Figure I

Use of a Bacterial Artificial Chromosome (BAC) as vector backbone for recombinant protein production. A) Schematic representation of the constructs used for protein production. CAGGS Fc is a conventional expression vector containing a CAGGS promoter, the Fc region of the human IgGI gene, an IRES-eYFP-SV40 polyA reporter element and a PGK neomycin cassette. The Rosa26BAC CAGGS Fc construct was generated by recombining the CAGGS Fc vector into a BAC containing the Rosa26 locus. The CAGGS Fc vector was placed into the exon 2 of antisense transcript of the Rosa26 locus with 100 kb upstream and downstream sequence. B) Comparison of the efficacy in protein production between a conventional vector and a BAC-based vector. The Fc yield was analyzed in HEK 293 bulk cultures generated with the CAGGS Fc and Rosa26BAC CAGGS $\mathrm{Fc}$ vectors. The CAGGS Fc vector gave a yield of $0.5 \mathrm{pg} /$ cell/day, while the BAC-based vector gave a yield of $5.7 \mathrm{pg} / \mathrm{cell} / \mathrm{day}$. Measurements were performed in triplicate. Error bars represent the standard deviation. 
the transgene copy numbers and ranged from 5.5 to 30 $\mathrm{pg} /$ cell/day (Figure 2A). The correlation coefficient $\mathrm{R}^{2}$ between the copy number of the BAC vector and protein production was 0.88 . This suggests that the protein production is proportional to the number of integrated transgene copies when using a BAC-based expression vector.

Finally, we investigated long-term protein production over time and increasing passage numbers. 6 subclones from the Rosa26 $6^{\mathrm{BAC} C A G G S}$ Fc culture were grown for 30 pas- sages and protein production was analyzed. The yield of the Fc protein was not significantly decreasing from passage 1 to passage 30 (Figure $2 \mathrm{~B}$ ) indicating that BACbased vectors provide stable long-term production of recombinant proteins.

\section{Discussion}

In this work, we have used a BAC containing the Rosa26 locus for protein production. The Rosa26 locus is considered to be a region of open chromatin (transcriptionally

\section{A}

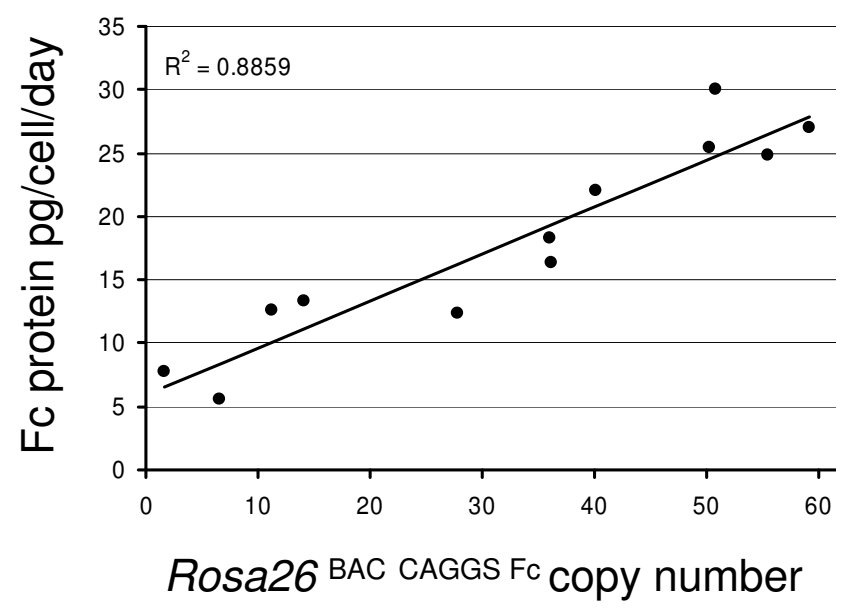

B

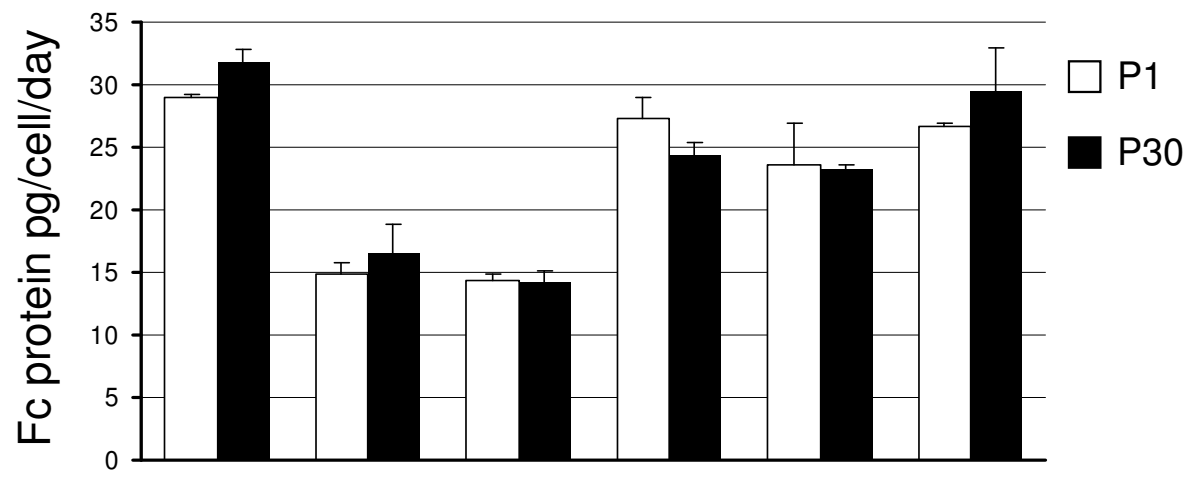

Rosa26 BAC CAGGS Fc clones

\section{Figure 2}

Protein expression using a BAC as vector backbone is transgene copy-number dependent and it is stable over time. A) Correlation between protein production and integrated BAC transgene copies. Analysis of 12 single clones showed a copy number range from I to 55 for the Rosa26BAC CAGGS Fc vector with a Fc yield of 5.5 to 30 pg/cell/day. The protein production was directly proportional to the BAC transgene copy number. B) Protein production is stably maintained during culture passaging. The yield of Fc protein was measured at passage I and passage 30 in 6 subclones isolated from the Rosa26 $6^{B A C}$ CAGGS Fc cultures. No obvious differences were found. Error bars represent the standard deviation. 
active) and has been successfully used to express genes of interest in transgenic mice [11]. With this approach, we have shown that a BAC-based vector improves recombinant protein production substantially when compared to a conventional vector. Further improvements of BACbased vectors for recombinant protein production could include the use of endogenous/natural promoters that are highly active in the producer cell. For example, a transcriptional profiling of HEK 293 cells has identified strong expression levels of the Rpl23a gene which encodes a ribosomal protein [12]. Therefore, the use of a BAC containing the Rpl23a locus in HEK 293 cells could further improve recombinant protein production.

\section{Conclusion}

The Rosa26 BAC fulfills the ideal characteristic of an expression vector applied to protein production in stable cell lines. It increases protein production by a factor of 10 when compared to a conventional vector and it confers copy number dependent and stable protein expression. These results suggest that BAC-based expression vectors overcome negative effects of the surrounding chromatin at the transgene integration site. Consequently, BACbased expression vectors represent an important tool to improve recombinant protein production.

\section{Authors' contributions}

$\mathrm{LB}$ and $\mathrm{M} M$ performed experiments. $\mathrm{AB}$ and RE performed and designed experiments. EC designed experiments and wrote the manuscript.

\section{Acknowledgements}

We thank Drs D. Stoiber and J. Kornfeld for critical reading and discussions. Olivia Simma for FACS analysis. D. Khan and K. Ettl for technical assistance. This work was supported by the Ludwig Boltzmann Gesellschaft. MM and RE have been financed by the SFB-F28 to RE.

\section{References}

I. Wurm FM: Production of recombinant protein therapeutics in cultivated mammalian cells. Nature biotechnology 2004, 22(II): 1393-1398.

2. Kwaks TH, Barnett P, Hemrika W, Siersma T, Sewalt RG, Satijn DP, Brons JF, van Blokland R, Kwakman P, Kruckeberg AL, et al.: Identification of anti-repressor elements that confer high and stable protein production in mammalian cells. Nature biotechnology 2003, 2 I (5):553-558.

3. Huang Y, Li Y, Wang YG, Gu X, Wang Y, Shen BF: An efficient and targeted gene integration system for high-level antibody expression. Journal of immunological methods 2007, 322(I-2):28-39.

4. Giraldo P, Montoliu L: Size matters: use of YACs, BACs and PACs in transgenic animals. Transgenic research 200I, 10(2):83-103.

5. Copeland NG, Jenkins NA, Court DL: Recombineering: a powerful new tool for mouse functional genomics. Nature reviews 200I, 2(10):769-779.

6. Yang $X \mathrm{~W}$, Model $\mathrm{P}$, Heintz $\mathrm{N}$ : Homologous recombination based modification in Escherichia coli and germline transmission in transgenic mice of a bacterial artificial chromosome. Nature biotechnology 1997, 15(9):859-865.

7. Zhang Y, Buchholz F, Muyrers JP, Stewart AF: A new logic for DNA engineering using recombination in Escherichia coli. Nature genetics 1998, 20(2): 123-128.
8. Blaas L, Musteanu M, Zenz R, Eferl R, Casanova E: PhiC3I-mediated cassette exchange into a bacterial artificial chromosome. BioTechniques 2007, 43(5):659-660.

9. Niwa H, Yamamura K, Miyazaki J: Efficient selection for highexpression transfectants with a novel eukaryotic vector. Gene 1991, 108(2): 193-199.

10. Felgenhauer $M$, Kohl J, Ruker F: Nucleotide sequences of the cDNAs encoding the V-regions of $\mathrm{H}$ - and L-chains of a human monoclonal antibody specific to HIV-I-gp4I. Nucleic acids research 1990, 18(16):4927.

II. Soriano P: Generalized lacZ expression with the ROSA26 Cre reporter strain. Nature genetics 1999, 2 I(I):70-7I.

12. Zagranichnaya TK, Wu X, Danos AM, Villereal ML: Gene expression profiles in HEK-293 cells with low or high store-operated calcium entry: can regulatory as well as regulated genes be identified? Physiological genomics 2005, 2I(I):14-33.
Publish with Biomed Central and every scientist can read your work free of charge

"BioMed Central will be the most significant development for disseminating the results of biomedical research in our lifetime. "

Sir Paul Nurse, Cancer Research UK

Your research papers will be:

- available free of charge to the entire biomedical community

- peer reviewed and published immediately upon acceptance

- cited in PubMed and archived on PubMed Central

- yours - you keep the copyright

Submit your manuscript here:

http://www.biomedcentral.com/info/publishing_adv.asp
BioMedcentral 